\title{
Effects of Valley Meteorology on Forest Pesticide Spraying
}

\author{
C. David Whiteman
}

April 1990

Prepared for the U.S. Forest Service Missoula Technology and Development Center under a Related Services Agreement with the U.S. Department of Energy Contract DE-AC06-76RLO 1830

Pacific Northwest Laboratory Operated for the U.S. Department of Energy by Battelle Memorial Institute 


\title{
DISCLAJMER
}

This report was prepared as an account of work sponsored by an agency of the United States Government. Neither the United States Government nor any agency thereof, nor Battelle Mernorial Institute, nor any of their ernployees, makes any warranty, expressed or implied, or assumes any legal liability or responsibility for the accuracy, completeness, or usefulness of any information, apparatus, product, or process disclosed, or represents that its use would not infringe privately owned rights. Reference herein to any specific commercial product, process, or service by trade name, trademark, manufacturer, or otherwise, does not necessarily constitute or imply its endorsement, recommendation, or favoring by the United States Government of any agency thereof, or Battelle Memorial institute. The views and opinions of authors expressed herein do not necessarily state or reflect those of the United States Government or any agency thereof.

\author{
PACIFIC NORTHWEST LABORATORY \\ operated by \\ BATTELLE MEMORIAL INSTITUTE \\ for the \\ UNITED STATES DEPARTMENT OF ENERGY \\ under Contract DE-AC06-76RLO 1830
}

Printed in the United States of America

Available to DOE and DOE contractors from the

Office of Scientific and Technical Information, P.O. Box 62, Oak Ridge, TN 37831;

prices available from (615) 576-8401. FTS 626-8401.

Available to the public from the National Technical Information Service,

U.S. Department of Commerce, 5285 Porl Royal Rd., Springfield, VA 22161.

NTIS Price Codes, Microfiche A01

Printed Copy

\begin{tabular}{cr}
\hline Price Code & Page Range \\
\hline A02 & $1-10$ \\
A03 & $11-50$ \\
A04 & $51-75$ \\
A05 & $76-100$ \\
A06 & $101-125$ \\
A07 & $126-150$ \\
A08 & $157-175$ \\
A09 & $176-200$ \\
A10 & $201-225$ \\
A11 & $226-250$ \\
A12 & $251-275$ \\
A13 & $276-300$ \\
A 14 & $301-325$
\end{tabular}

\begin{tabular}{cc}
\hline Price Code & Page Range \\
\hline A15 & $326-350$ \\
A16 & $351-375$ \\
A17 & $376-400$ \\
A18 & $401-425$ \\
A19 & $426-450$ \\
A20 & $451-475$ \\
A21 & $476-500$ \\
A22 & $501-525$ \\
A23 & $526-550$ \\
A24 & $551-575$ \\
A25 & $576-600$ \\
A99 & $601-U p$
\end{tabular}


PNL-7332

UC-402

\section{EFFECTS OF VALLEY METEOROLOGY ON FOREST PESTICIDE SPRAYING}

C. David Whiteman

April 1990

Prepared for the

U.S. Forest Service

Missoula Technology and Development Center under a Related Services Agreement

with the U.S. Department of Energy

Contract DE-AC06-76RLO 1830

Pacific Northwest Laboratory Richland, Washington 99352 


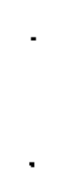




\section{SUMMARY}

Recent research has shown that many valleys, when undisturbed by external conditions such as cloudiness or high upper-level winds, undergo a regular diurnal evolution. Destruction of the nocturnal temperature inversion and reversal of the nocturnal down-valley flow occurs during a 3-1/2 to 5-hour period following sunrise, called the morning transition period. The processes responsible for temperature inversion breakup and wind system reversal are largely driven by the development of upslope flows in convective boundary layers (CBLs) that develop over the heated sidewalls. Aerial spraying of forest pesticides takes place in these growing CBLs. The important physical processes can be summarized:

- Spray released over the slopes before local sunise will be carried down the slopes and down the valley but will remain fairly concentrated owing to reduced dispersion in the high stability atmospheric conditions. Nondeposited spray may adversely affect sensitive areas that may be located down-valley from the spray project.

- Upslope flows will form within a matter of minutes over sunlit slopes. Drift of a non-deposited plume will initially be upsiope. If the spray plume escapes the boundary layer, however, or if the spraying occurs too high above the slope, it will be transported down the valley.

- The rate of development of the CBLs varies from location to location within the valley depending on time of sunrise, solar flux, surface energy budget, and temperature inversion destruction mechanism. When a boundary layer becomes deep and turbulent, spraying operations are no longer effective. This typically occurs first on the ridgetops and upper slopes. The lower slopes, because of the presence of the remnants of the nocturnal inversion above them, usually grow much more slowly and can be sprayed effectively much later in the morning. Late in the morning, the winds reverse to upvalley in the elevated remnants of the nocturnal inversion. Non-deposited pesticide will then drift up the slope and up the valley axis.

- After the temperature inversion is destroyed, the valley atmosphere will become part of a deep CBL. If coupled with strong winds aloft, the valley winds will be strong and turbulent, making conditions unsuitable for aerial spraying operations.

Recent gains in understanding of valley meteorology suggest that new modeling tools can now be applied to improve the planning and conduct of forest aerial spaying operations. Such tools may include digital topography models, solar shading algorithms, inversion breakup models, and flight path optimization models. Simple dispersion models could be modified to provide useful planning tools for forest spraying operations, and a long-term program could be initiated to apply recent boundary-layer growth models to threedimensional topography. 
. 


\section{CONTENTS}

SUMMARY

INTRODUCTION

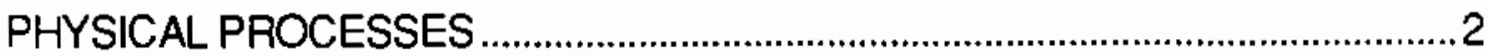

BUILDUP OF VALLEY TEMPERATURE INVERSIONS ...........................

BREAKUP OF VALLEY TEMPERATURE INVERSIONS...........................

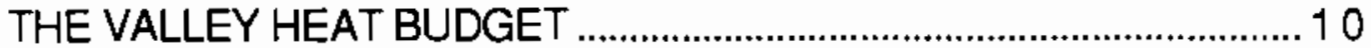

GENERAL CONSIDERATIONS: PESTICIDE DISPERSION IN

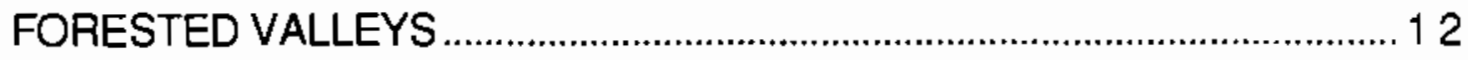

CONCLUSIONS REGARDING FOREST PESTICIDE SPRAYING ................... 14

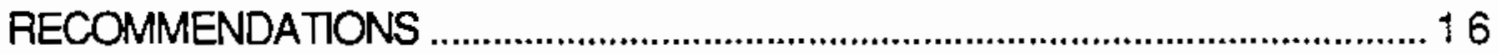

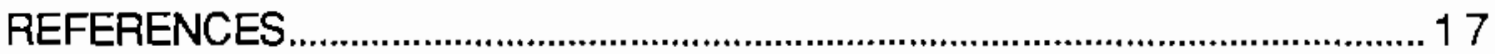




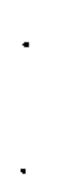




\section{FIGURES}

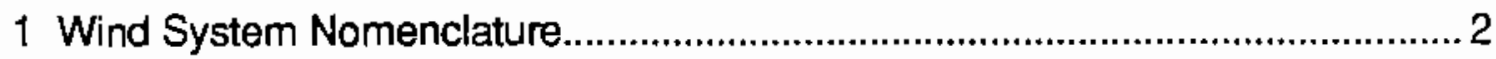

2 Schematic Depiction of Wind and Temperature Structure Evolution in Valleys

3 Three Patterns of Temperature Structure Evolution with Height $(z)$ and Time (t) during the Inversion Breakup Period.. 5

4 Typical Mid-morning Wind Structure Over and Within a Deep Valley on the Western Slope of the Rockies, Illustrating the Five Interrelated Wind Systems Identified in Field Studies

5 Relationship Between Temperature Structure Layers and Wind Systems

6 Dual Soundings from a Valley Floor and a Valley Sidewall lliustrating the Upslope Flow Found Within the CBL Over the Sidewall........................... 8

7 Illustration of the Hypothesis of Inversion Destruction......................................9

8 The Varying Times of Local Sunrise (Mountain Standard Time), Shown Here for Montana's Marshall Creek Canyon on May 16 Will Produce Spatial Contrasts in Boundary Layer Growth.

9 Dispersion Implications of CBL Growth and Inversion Top Descent 13 


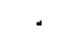




\subsection{INTRODUCTION}

Pacific Northwest Laboratory conducted this study for the Missoula Technology and Development Center of the U. S. Department of Agriculture's Forest Service. The purpose of the study was to summarize recent research on valley - meteorology during the morning transition period and to qualitatively evaluate the effects of the evolution of valley temperature inversions and wind systems on the aerial spraying of pesticides in National Forest areas of the western United States.

Aerial spraying of pesticides and herbicides in forests of the western United States is usually accomplished in the morning hours after first light, during the period known to meteorologists as the "morning transition period." The morning transition period is the post-sunrise period when the nocturnal down-valley flows are reversed to daytime up-valley flows and when the nocturnal temperature inversions are destroyed. The spraying continues until convective boundary layers and upslope flows develop sufficiently to render it difficult to place the spray where needed in the canopy. On an undisturbed clear day, the spraying must be terminated in mid to late morning. The normal sequence of meteorological events during the morning transition period is now well known, although the timing of these events varies significantly from valley to valley and from location to location within the same valley. This document describes the key physical processes that occur during the morning transition period on undisturbed days and the qualitative effects of these processes on the conduct of aerial spraying operations. Since the timing of valley meteorological events may be strongly influenced by conditions that are external to the valley, such as strong upper-level winds or the influence of clouds on the receipt of solar energy in the valley, some remarks are made on the qualitative influence of these processes. Section 4 of this report suggests ways to quantify some of the physical processes to provide useful guidance for the planning and conduct of spraying operations. 


\subsection{PHYSICAL PROCESSES}

In this section, we summarize valley temperature inversion destruction observations collected in a number of Colorado valleys, pointing out typical characteristics of the meteorology of these valleys and the physical processes that must be included in realistic spray dispersion models simulating the inversion destruction period. In the last 10 years it has become clear that the inversion breakup patterns first observed in Colorado valleys in the 1970 s are typical of patterns found in many other mountainous regions (Whiteman 1990), so that the understanding gained in the study of Colorado valleys is expected to be of widespread applicability. The following summary deals with conditions when upper winds are weak and weather conditions are undisturbed by largescale traveling storm systems, such that the circulations within the valley are entirely locally produced. These local circulations are thermally driven, forced by pressure differences that arise owing to different rates of heating and cooling between the valley and its surroundings and between different locations within the topography. In such conditions the two main classes of local circulations are the up- and down-valley flows and the up- and down-slope flows (Figure 1) that have long been recognized in mountainous regions.
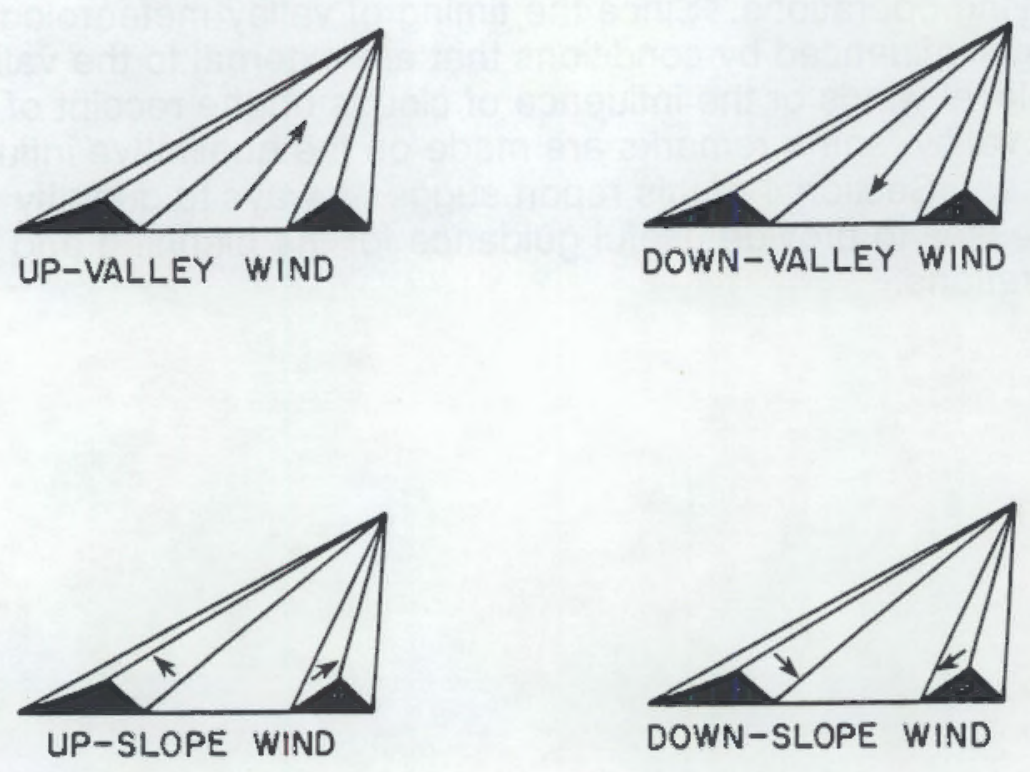

FIGURE 1. Wind System Nomenclature 


\subsection{Buildup of Valley Temperature Inversions}

Cold air drains off the ridgetops and slopes of a valley during nighttime and collects in the valley, forming a surface-based temperature inversion (Figure 2a). In such an inversion, the coldest temperatures are found adjacent to the surface, and temperatures increase with altitude until the top of the inversion is reached. In the high-elevation, continental, mountainous western United States, the cooling power is strong enough on most clear nights to produce a surface-based temperature inversion that extends through the entire valley depth. Winds within the temperature inversion blow down the valley axis, although there are shallow downslope flows over the inclined sidewalls. The coldest temperatures and the strongest inversions generally occur at astronomical sunrise. This nocturnal inversion is generally destroyed following sunrise (Figures $2 b$ through $2 d$ ), as solar energy provides the necessary heating at the surface. The ground or vegetative canopy absorb solar radiation and, in turn, heat the adjacent air. As the air warms it becomes less dense and eventually moves upward replacing cooler denser air in a process referred to as convection. Further details regarding the physical processes leading to the valley wind and temperature structure evolution during this period follow, illustrated by the Colorado observations.

\subsection{Breakup of Valley Temperature Inversions}

Temperature inversions in Colorado valleys are destroyed after sunrise following one of three patterns (Whiteman 1982) of temperature structure evolution (Figure 3 ). Note that Figure 3 uses potential temperature rather than actual temperature for the abscissa; potential temperature is preferred since actual temperature is a non-conservative variable under vertical motion because of the dependence of temperature on pressure. For those unfamiliar with this new variable, to a first approximation simply consider potential temperature to be actual temperature, and consider a constant potential temperature layer to be a well-mixed or convective boundary layer (CBL).

The first pattern, observed in the widest valley studied, approximates inversion destruction over flat terrain, in which the nocturnal inversion is destroyed after sunrise by the upward growth from the ground of a warming CBL. The elevated inversion or cold pool is eroded from the bottom but does not descend. The second pattern, observed in snow-covered valleys, differs significantly from the first. Here the growth of a CBL, which begins after sunrise, is arrested once the CBL has attained a depth of 25 to $50 \mathrm{~m}$. The inversion is then destroyed as the top of the nocturnal inversion descends into the valley. Warming of the central region of the cross section is consistent with adiabatic subsidence heating produced by the descending motions. The third pattern of temperature structure evolution was observed in all of the valleys when snow cover was not present and describes the majority of case studies observed in field experiments. In this pattern, inversions are destroyed by a combination of two processes: the 

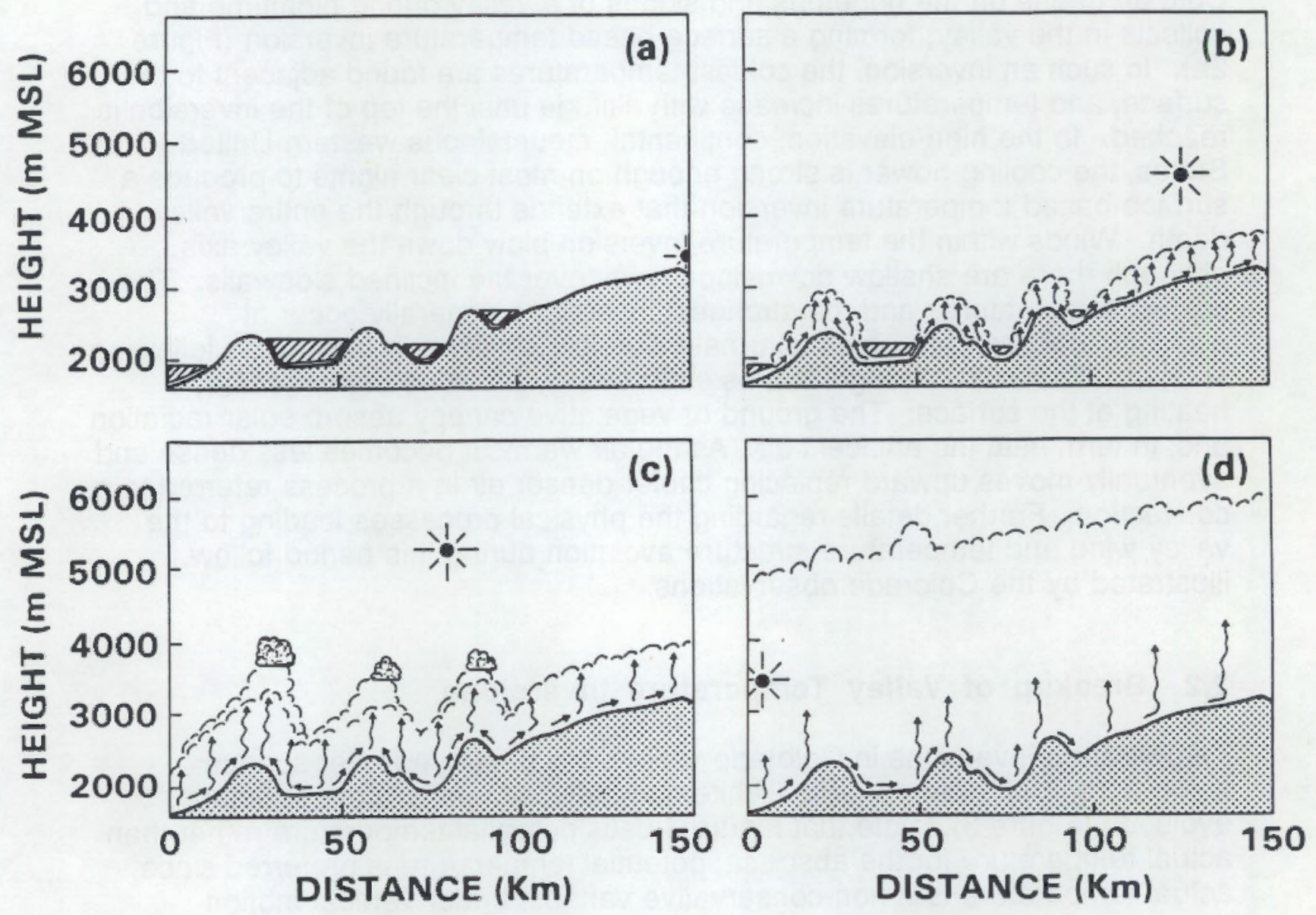

FIGURE 2. Schematic Depiction of Wind and Temperature Structure Evolution in Valleys. (a) At sunrise, the cold air has built up in the valley depressions forming surface-based temperature inversions. (b) After sunrise, convection and upslope flows begin to form over the heated slopes. Over the ridgetops, the convection results in rapid boundary layer growth, while, in the valley, the depth of convection is constrained by the overlying remnants of the nocturnal inversion. (c) By midday, the valley temperature inversions are destroyed and convection occurs in turbulent boundary layers over all heated surfaces. (d) By late in the day, the convective boundary layer reaches its maximum height over the mountain range and weak downslope flows occur over valley sidewalls that become shaded by the surrounding topography. 

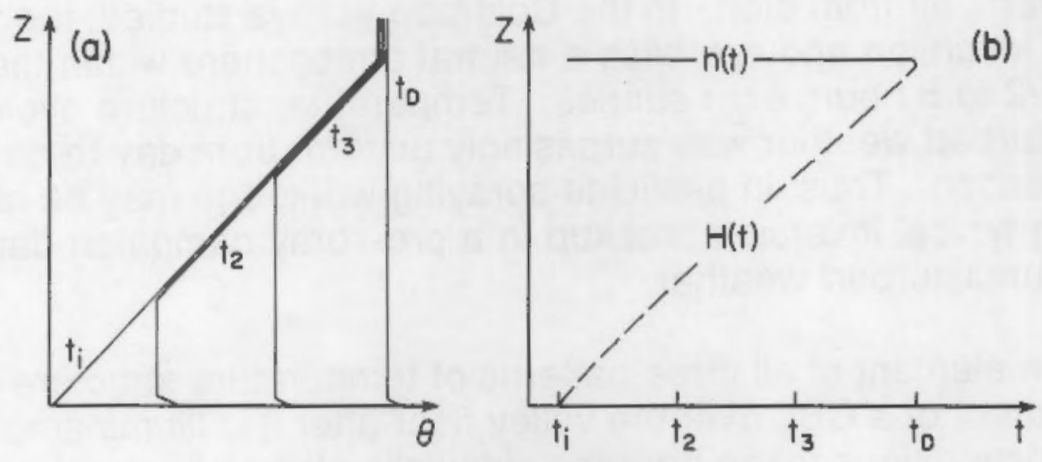

Pattern 1. Growth of CBL.
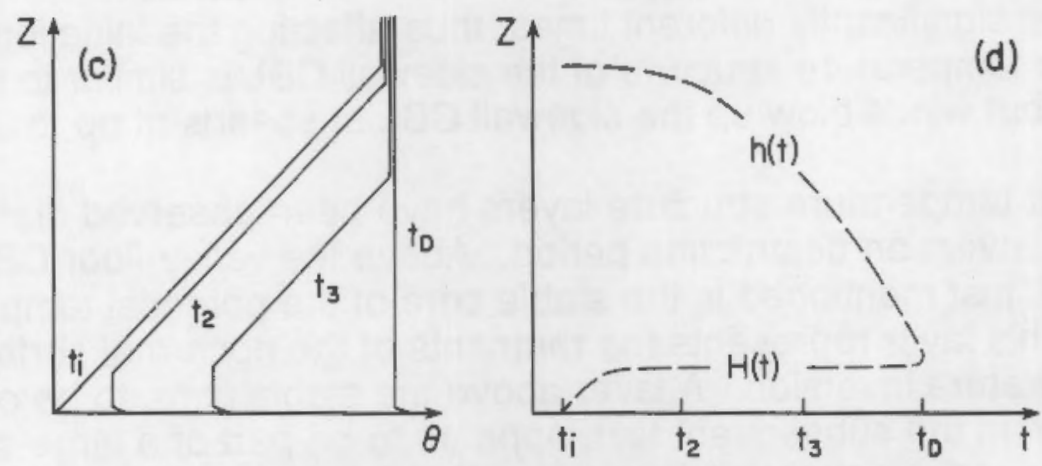

Pattern 2. Descent of inversion top and arrested growth of $\mathrm{CBL}$.
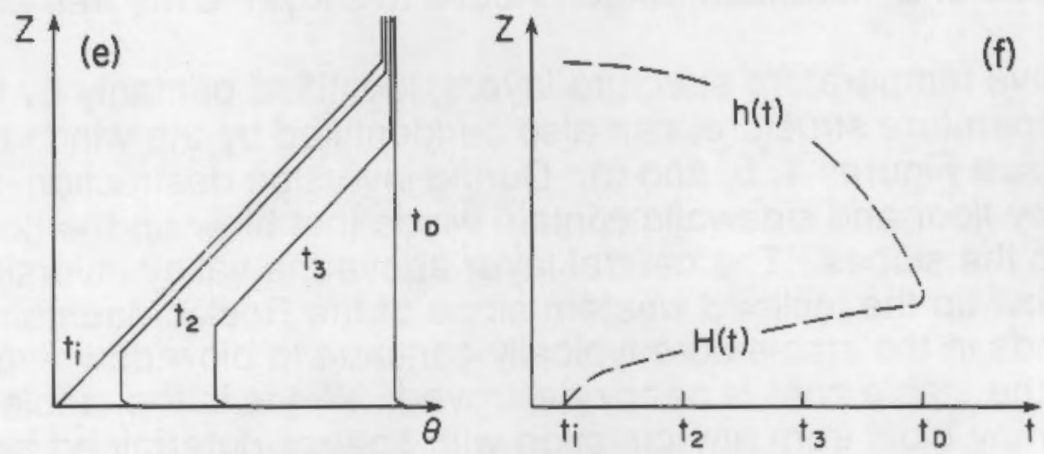

Pattern 3. Descent of inversion top and continuous growth of CBL.

FIGURE 3. Three Patterns of Temperature Structure Evolution with Height ( $z$ ) and Time (t) during the Inversion Breakup Period. Potential temperature profiles $(\theta)$ are on the left, and time-height analyses of convective boundary layer height $(\mathrm{H})$ and inversion top height $(\mathrm{h})$ are on the right. 
continuous upward growth from the valley floor of a warming CBL and the continuous descent of the top of the nocturnal temperature inversion. Again, as for the second pattern of inversion destruction, warming of the elevated inversion layer above the CBL is caused by vertical advection, i.e., by simple sinking of warm air from aloft. In the Colorado valleys studied, the time required to break an inversion and establish a neutral atmosphere within the valley was typically $3-1 / 2$ to 5 hours after sunrise. Temperature structure evolution during clear, undisturbed weather was surprisingly uniform from day to day and from season to season. Thus, in pesticide spraying work, one may be fairly confident of observing typical inversion breakup in a pre-spray campaign data collection program in undisturbed weather.

The common element of all three patterns of temperature structure evolution is the development of a CBL over the valley floor after it is illuminated by direct sunlight. Observations taken from the sidewalls also show the development of a CBL after direct sunlight illuminates the sidewall. Because of the shading effects of surrounding topography, the different valley surfaces can be illuminated at significantly different times, thus affecting the initiation of CBL growth. The temperature structure of the sidewall CBL is similar to that over the valley floor, but winds blow up the sidewall CBL at speeds of up to $3 \mathrm{~m} / \mathrm{s}$.

Five different temperature structure layers have been observed during the temperature inversion destruction period. Above the valley floor CBL and the sidewall CBL just mentioned is the stable core of the potential temperature inversion. This layer represents the remnants of the nocturnal surface-based valley temperature inversion. A layer above the stable core, to be called the 'neutral layer' in the subsequent text, appears to be part of a large-scale convective boundary layer that forms over the western slope of the Rocky Mountains. Such an intermediate circulation might form above any valley that is cut into the side of a mountain range. Above this layer is the free atmosphere.

Each of the five temperature structure layers, identified primarily by their potential temperature structure, can also be identified by the winds that prevail within them (see Figures 4, 5, and 6). During inversion destruction, the CBLs over the valley floor and sidewalls contain winds that blow up the floor of the valley and up the slopes. The neutral layer above the valley inversion has winds that blow up the inclined western slope of the Rocky Mountains during the day. Winds in the stable core typically continue to blow down-valley after sunrise until the stable core is nearly destroyed. Winds in the stable free atmosphere may blow from any direction with speeds determined by synopticscale pressure gradients. Despite variability in the strength and timing of reversal of the winds, the temperature structure evolves uniformly from day to day in individual valleys.

On the basis of the wind and temperature observations summarized above, an hypothesis has been developed to explain the temperature structure evolution (Figure 7). Since energy is required to change the temperature structure, and 


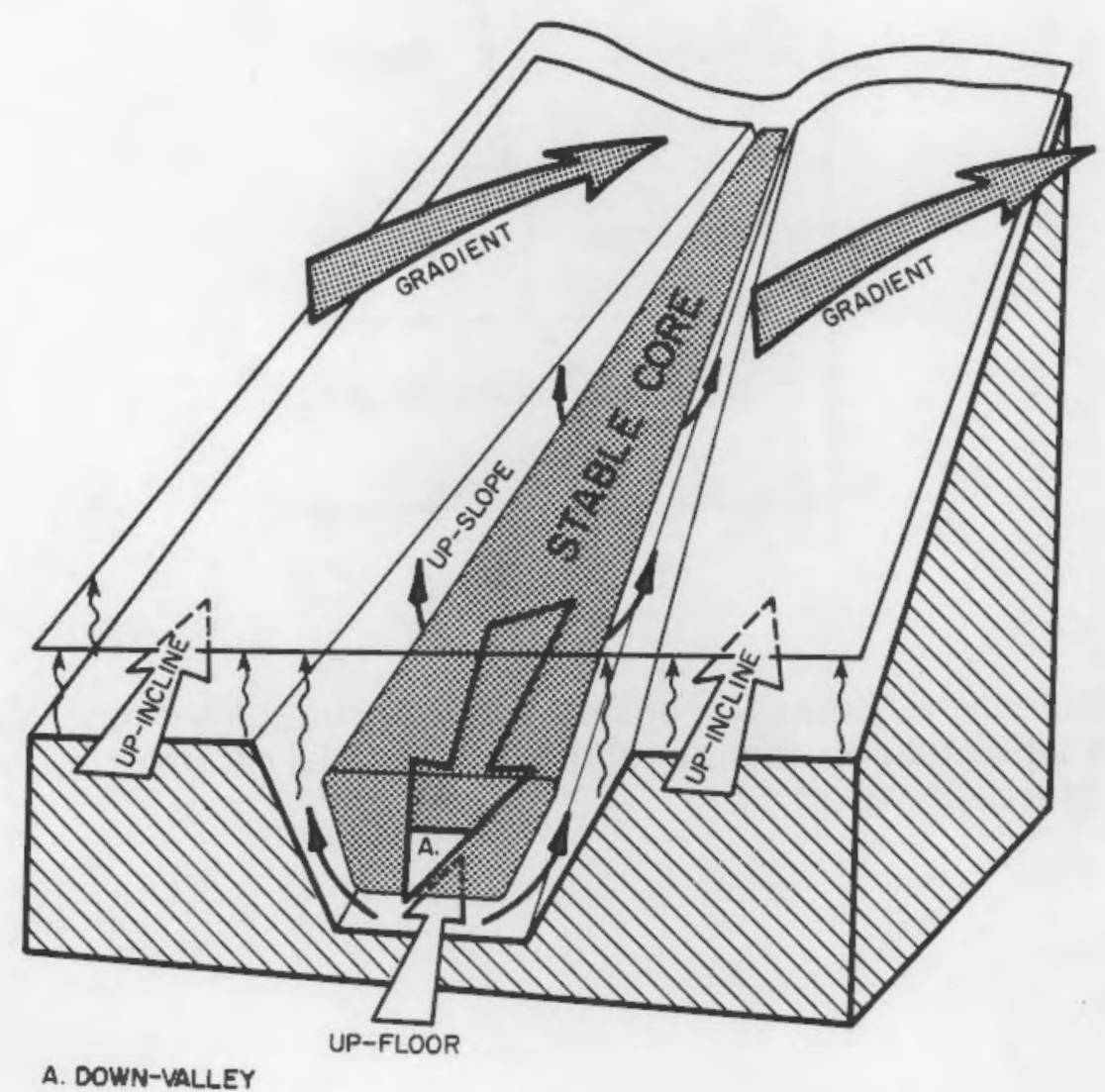

FIGURE 4. Typical Mid-morning Wind Structure Over and Within a Deep Valley on the Western Slope of the Rockies, Illustrating the Five Interrelated Wind Systems Identified in Field Studies. 


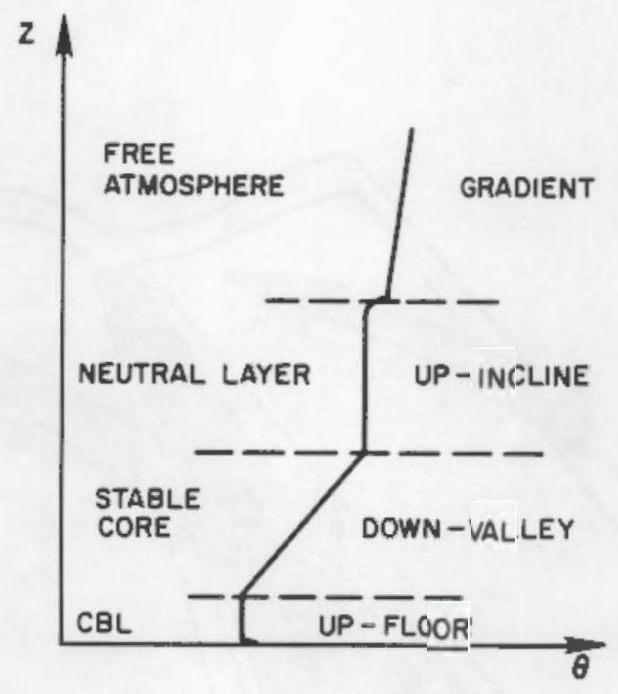

FIGURE 5. Relationship Between Temperature Structure Layers and Wind Systems. The temperature structure represents a typical mid-morning sounding from the floor of a deep valley.

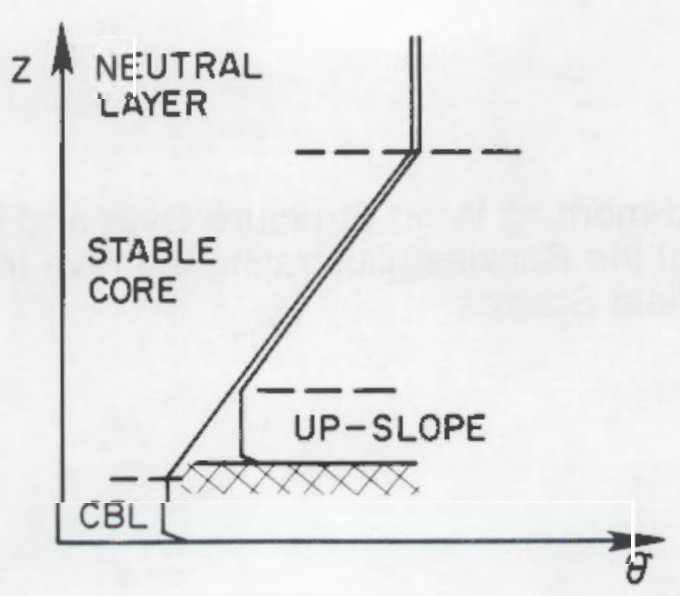

FIGURE 6. Dual Soundings from a Valley Floor and a Valley Sidewall Illustrating the Upslope Flow Found Within the CBL Over the Sidewall. 

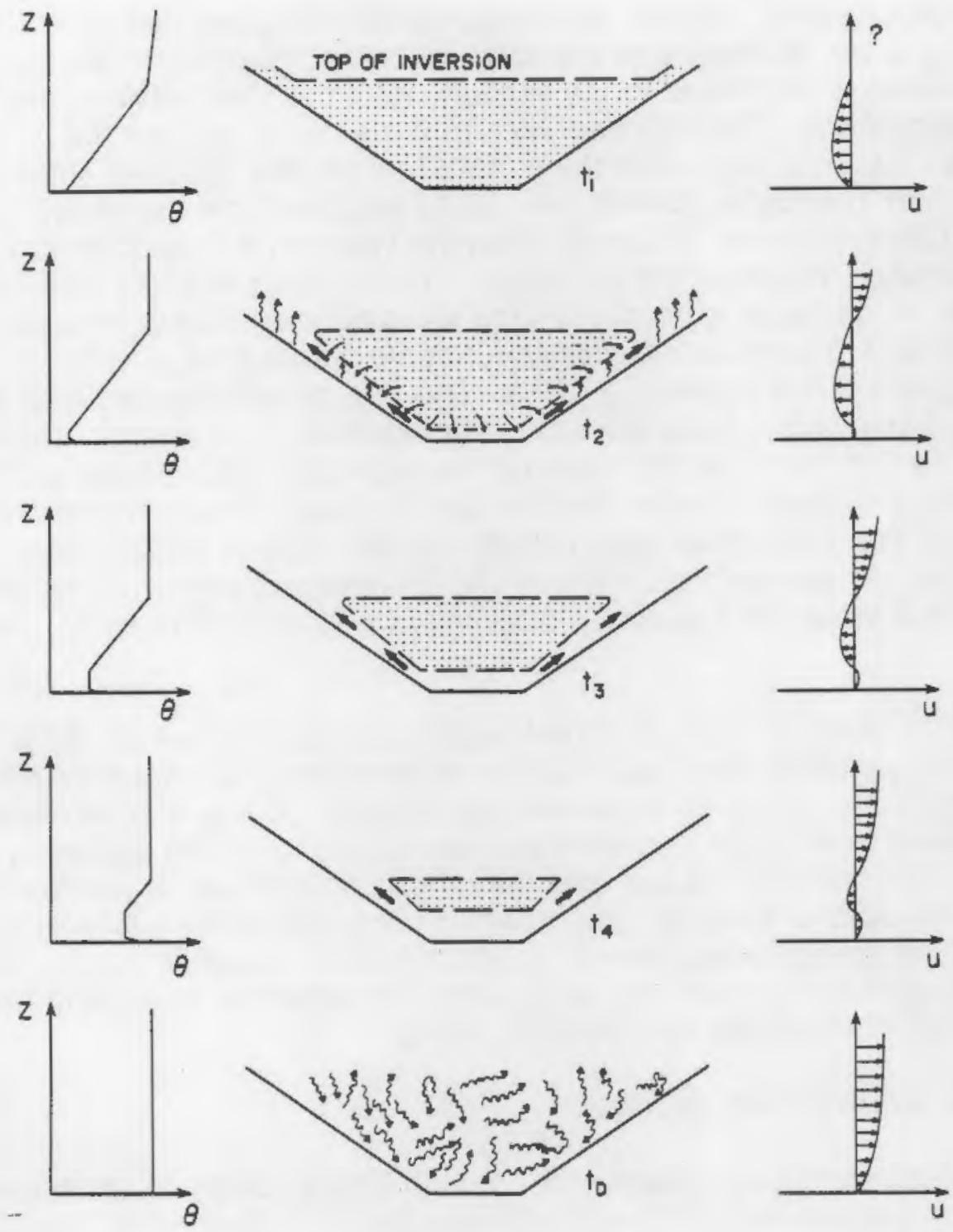

FIGURE 7. Illustration of the Hypothesis of Inversion Destruction. In the center of the diagram cross sections of a valley are shown at times $t_{i}, t_{2}, t_{3}, t_{4}$, and $t_{D}$. On the left are corresponding potential temperature profiles as taken from the valley center. On the right are corresponding up-valley wind components $(u)$ as a function of height. At sunrise, $t_{i}$, an inversion is present in the valley. At $t_{2}$, a time after sunlight has illuminated the valley floor and slopes, a growing CBL is present over the valley surfaces. Mass and heat are entrained into the CBLs from the stable core above and carried up the sidewalls in the upslope flows. This results in a sinking of the stable core and growth of the CBLs ( $t_{3}$ and $t_{4}$ ) until the inversion is broken (tD) and a turbulent, well-mixed neutral atmosphere prevails throughout the valley depth. Down-valley winds continue to blow in the stable core during the inversion breakup period. Winds in the CBL below and in the region above the stable core often blow up-valley during this same period. 
the change begins at sunrise, it is reasonable to propose that solar radiation is the driving force. A fraction of the solar radiation, received on the valley floor and sidewalls, is converted to the sensible heat flux that provides energy to the valley atmosphere. Sensible heat flux from a surface, as over flat terrain, causes a CBL to develop over the surface. Mass and heat are entrained into the CBL from the stable core above. Mass entrained into the valley floor and sidewall CBLs, however, is carried from the valley in the upslope flows that develop in the CBLs over the sidewalls. This removal of mass from the base and sides of the stable core causes the elevated inversion to sink deeper into the valley and to warm adiabatically during its subsidence and decreases the rate of growth of the underlying CBLs. The rate of warming depends directly on the rate of energy input into the valley atmosphere. This energy may be used to deepen the CBLs or to move mass up the sidewalls, allowing the stable core to sink. From this hypothesis a thermodynamic model of temperature inversion destruction has been developed (Whiteman and McKee 1982). This thermodynamic model forms the basis for parameterizations of inversion breakup in a valley air pollution model called VALMET (Whiteman and Allwine 1985).

Research in Colorado's Brush Creek valley in 1984 (Whiteman 1989, Bader and Whiteman 1989) identified a further physical process that may affect plume dispersion in narrow north-south oriented valleys. There, a cross-valley advection occurred during times of the day when one of the sidewalls was strongly illuminated by the sun and the other sidewall was in shadow or received weak solar heating. The effect of the cross-valley advection was to transport elevated plumes toward the strongly illuminated sidewall. This effect has been seen in other valleys (e.g., Urfer-Henneberger 1970) and has been investigated theoretically by Gleeson (1951).

\subsection{The Valley Heat Budget}

Moist surface conditions, cloudiness, or high albedo owing to snow cover may change the surface energy budget components so that sensible heat flux is reduced. In these conditions, inversion destruction will be delayed or an inversion may persist all day (see, e.g., the Yampa Valley observations of Whiteman and McKee 1982). These conditions are often advantageous for forest spraying, since the boundary layers over the sidewalls develop more slowly on such days, and acceptable spraying conditions persist much longer into the morning and afternoon than would be the case with clear skies and strong sensible heat flux.

Further, in a valley of complicated topography, the propagation of shadows from surrounding topography will ensure that some of the valley's slopes may be in shadow while others are in sunlight. Thus, we may speak of local sunrise times at points in the valley being later than the time of astronomical sunrise. Often the propagation of shadows is quite predictable to the casual observer, viz., the slow propagation of a shadow down one of the sidewalls, but in deeply dissected topography the propagation of shadows may be quite complicated, especially where the valley axis follows a sinuous course (see, e.g., Figure 8). 


\section{SUNFISE TIMES, MAY 16}

\section{Marshall Creek Canyon, Montena}
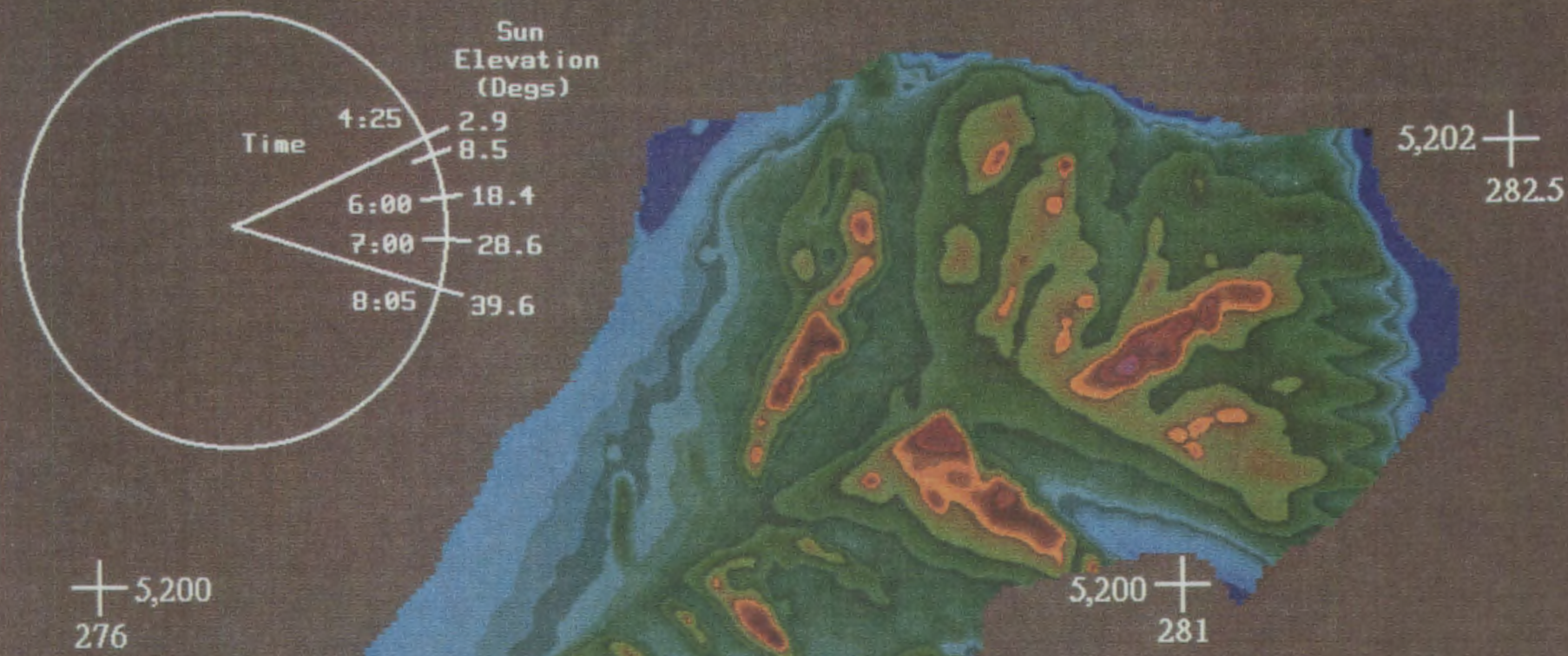

276

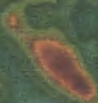

$$
5,200 \frac{1}{281}
$$

Contour Interval $=30$ Minutes

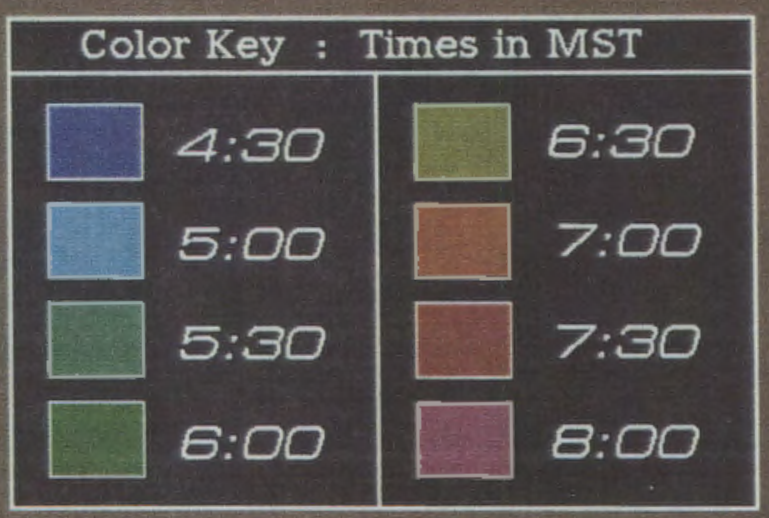

$+5,197$

276

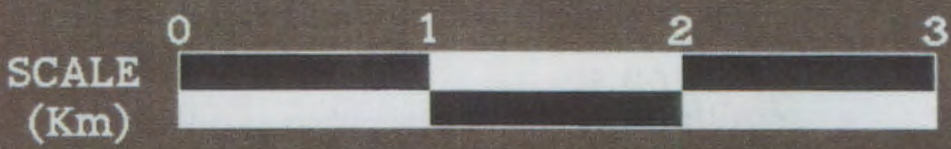

Tick Marks : UTM Zone 12 Coordinates in Kilometers

FIGURE 8. The Varying Times of Local Sunrise (Mountain Standard Time), Shown Here for Montana's Marshall Creek Canyon on May 16 Will Produce Spatial Contrasts in Boundary Layer Growth. Quantitative information from solar radiation and solar shading models such as the one shown here could be used to plan and optimize forest pesticide spraying operations in the country's national forests. 


\subsection{GENERAL CONSIDERATIONS: PESTICIDE DISPERSION IN FORESTED VALLEYS}

The valley inversion destruction mechanism outlined above has important implications for the dispersion of pesticide sprays. These implications will be investigated first by assuming that the nocturnal inversion at sunrise contains pesticides that have been sprayed along the valley's axis in the mid-valley atmosphere. Other assumptions will be made subsequently. Typically, at sunrise, the plume would be carried down the valley in the nocturnal drainage flows, undergoing both vertical and horizontal dispersion. It is of interest that horizontal dispersion in these flows is known to be much greater than over flat terrain (Start et al., 1975) - a factor which may decrease the concentrations of a plume transported over a valley centerline relative to that over a plain. This important factor is, however, counterbalanced somewhat by the fact that the plume is channeled by the valley and that the plume centerline may directly impact an elevated terrain feature. We will focus initially on the dispersion of the pesticide on a valley cross section (Figure 9). After sunrise a convective boundary layer forms over the valley floor and sidewalls (Figure 9a). The subsequent dispersion in the stable core will be affected by two competing processes -- the sinking of the stable core and the growth of the CBL. The three inversion breakup patterns discussed above have the following dispersion implications:

1. Pattern 1 - Growth of convective boundary layer (Figure 9b): Pure growth of a CBL will result in the fumigation (Hewson et al., 1961) of a spray cloud at the valley floor as the $C B L$ grows upward into the stable core. This process is favored when the slope flows are ineffective in removing mass from a valley and will thus occur in very wide and/or shallow valleys.

2. Pattern 2 - Sinking of stable core (Figure 9c): Failure of the CBL to grow once it has formed over the valley floor and sidewalls results in inversion destruction by sinking of the stable core. Thus, the spray cloud sinks into the top of a shallow mixed layer, producing high concentrations at the ground. The spray plume, once entrained into the CBL, is advected up the sidewalls and dispersed into the neutral layer aloft. This process is favored for narrow-to-wide valleys when sensible heat flux is weak.

3. Pattern 3 - Combination (Figure 9d): A combination of CBL growth and stable core descent results in the sinking of the spray cloud into the top of a growing mixed layer. Spray concentrations should be intermediate between the two previous cases. This pattern is the most common one in Colorado Mountain valleys.

The above discussion focuses on plume dispersion on a valley cross section. However, winds in the stable core, as mentioned above, blow down the valley until the inversion is nearly broken. Thus, pesticide sprayed into the stable core encounters a stable environment where diffusion is quite limited and will be carried down the valley, often toward populated or other sensitive areas. 

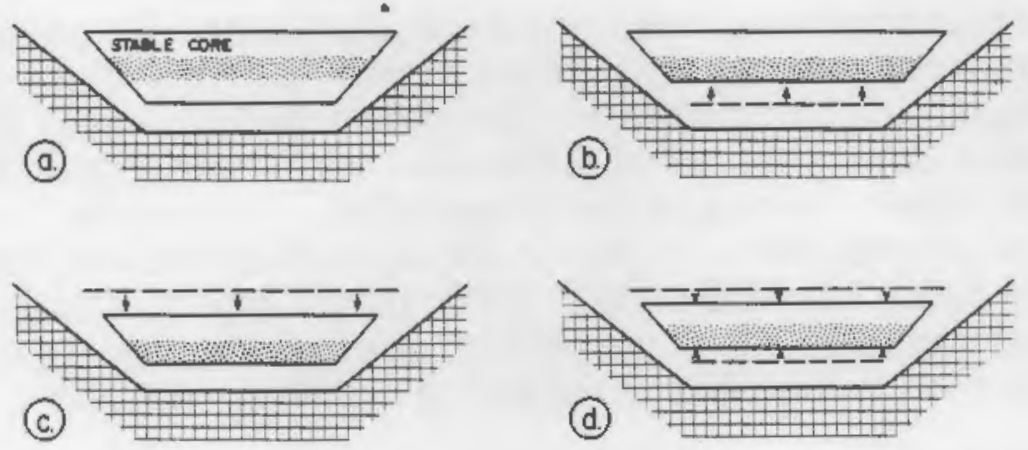

FIGURE 9. Dispersion Implications of CBL Growth and Inversion Top Descent.

Actual forest pesticide spraying, rather than occurring at an elevated position in the mid-valley atmosphere, is conducted by spray aircraft over the sidewalls above the forest canopy. Thus, after local sunrise the spray is released into the growing $\mathrm{CBL}$, rather than into the stable core. When this boundary layer is shallow and the upslope winds within the layer are weak, the pesticide plume will deposit well in the canopy, aided by the downward motions from wingtip vortices. Any non-deposited chemical will generally drift up the slope and concentrations will be decreased by mixing caused by the turbulent winds within the upslope-flowing layer. A different situation arises, however, when the pesticide is sprayed later in the morning into a deep, fully-developed slope boundary layer. Then, flying conditions will be rough, and the spray plume may be broken up by strong convective eddies. A smaller proportion of the plume will be deposited and a larger drift will occur. Fortunately, however, this drift will be up-slope and pesticide will be well mixed through the deep layer so that concentrations will be low. The drift of the plume will rarely be toward sensitive population centers, since such centers are generally located down-slope on the valley floor. The most ideal spraying conditions should occur after the slope is illuminated by the sun, but before the convective boundary layer becomes deep and fully developed. The CBL on the ridgetops and at the upper levels of the sideslopes develops very rapidly after sunrise, since the stable core descends into the valley and these convective layers are not constrained by an overlying inversion layer. As these boundary layers develop, mixing may increase the exposure of the ridgetops to strong upper-level winds, further decreasing the chances of getting pesticide deposition on target vegetation. 


\subsection{CONCLUSIONS REGARDING FOREST PESTICIDE SPRAYING}

The above description of valley meteorology during the morning transition period results in the following implications for forest spraying activities:

- Spray released before sunrise or over shaded slopes will be released into shallow stable boundary layers over the slopes. Drainage flows in these boundary layers will be downslope. The overlying down-valley flows typically superimpose a down-valley wind component on these layers, so that any drift of the spray will move downslope and down-valley. Pre-sunrise spraying may adversely affect population centers or sensitive areas that are downslope or down-valley during this time period. When plume impacts occur, concentrations may be quite high because of the poor diffusion environment along the transport path in the remnants of the strong nighttime inversion.

- Initially, shallow CBLs form over sunlit slopes. Shortly after they are sunlit (typically 10 to 15 minutes), an upslope flow will form. Drift of a non-deposited plume will then be upslope. If the plume escapes from the boundary layer (or if the spraying occurs too high above the slope), it will be transported down the valley in the remnants of the stable core.

- Convective boundary layers develop rapidly over the ridgetops and upper slopes after they become sunlit, because they are not capped by the strongly stable nocturnal inversion. Especially rapid CBL development may occur over the upper slopes that face the morning sun. When upper winds are moderate or strong, growth of the CBLs will bring the stronger winds down onto the upper slopes. The upper slopes would then become more and more turbulent, with the normal thermal convection processes being supplemented by transport of horizontal momentum from aloft. The rate of CBL development over the upper slopes will strongly affect the spraying environment there.

- Once temperature inversion destruction begins, the top of the temperature inversion will sink into the valley, exposing more of the upper slopes to intense CBL development. Winds within the stable core during this time will continue to blow down the valley, but the speed will typically be decreasing until, just before the inversion is destroyed (3-1/2 to 5 hours after astronomical sunrise on a clear day), the winds will switch to up-valley throughout the valley's volume.

- During the inversion destruction period, boundary layers on the lower slopes will be growing much more slowly because of the strongly stable layer (the remnants of the nocturnal inversion) that overlies them.

- Given the above processes, rates of CBL development depend strongly on the local amount of insolation (which varies from place to place within the valley), the surface energy budget, and the overlying temperature structure. The ridgetops and upper slopes should be sprayed first, because the dispersion environment there rapidly becomes too turbulent for continued spraying. The spraying environment on the lower slopes, in contrast, is suitable for spraying 
for a much longer time. Spraying conditions can be quite different on opposing slopes during the morning transition period, especially in north-south oriented valleys where the opposing slopes have quite different heating functions. The east-facing slope will receive solar input earlier, the CBL will develop earlier and more rapidly, and the differential heating of the two slopes may result in a cross-valley flow toward the heated slope.

- After the temperature inversion is destroyed, the valley becomes well coupled with the winds aloft. If these winds are weak, a thermally driven up-valley circulation will prevail within the valley. The absence of a strong capping inversion above the surfaces will result in a deep and turbulent CBL over all the valley's surtaces. If the upper winds are strong, they may superimpose their own wind direction on the valley, and winds may be correspondingly stronger and more turbulent, making conditions unsuitable for aerial spraying operations. 


\subsection{RECOMMENDATIONS}

Our present understanding of valley meteorology during the morning transition period has progressed to the point where some useful planning tools could be constructed to optimize a forest pesticide spraying campaign. Simple models could be developed for use in the field to optimize the vectoring of spray planes so that spraying could be accomplished in the most suitable locations within a drainage area before convective boundary layers became too deep and strong. The area of effective pesticide coverage in a given spray campaign could be optimized by such a model. Digital topography models and solar shading algorithms could be developed to aid in this determination. Inversion breakup models and some simple air pollution dispersion models (Whiteman and McKee 1982, Whiteman and Allwine 1985) could be modified for support of forest spraying campaigns. Finally, some promising models of boundary layer growth on slopes have been formulated in the last several years that could be applied to the forest spraying problem. A model by Brehm (1986) was published in 1986, while two recent models, one by Dr. U. Schumann at the German Aerospace Research Establishment and one by Dr. J. Egger of the University of Munich, are presently in press. These models could be formulated in three dimensions, raising the possibility of using actual digital terrain, solar shading, and boundary layer growth models in a single package. Such boundary layer growth models have not yet been tested in real valleys, so that field experiment campaigns should be an important component of future work.

While the approaches mentioned in the previous paragraph could be applied now, several key research questions remain that will need to be addressed in order to make further progress. Some of these issues are being addressed now in ongoing research funded by the U.S. Department of Energy's Atmospheric Studies in Complex Terrain (ASCOT) program and in other federal programs. Very little work has, so far, been accomplished dealing with variations in surface energy budgets over complex terrain areas. Such energy budgets, which have a strong influence on the development of local circulations and growth of boundary layers, will be affected by clouds. Few studies have dealt with the influence of clouds. Further, much meteorological research remains to be done on forest canopies and their effects on valley heat budgets and locaily developed circulations. Finally, the influence of external processes on valley circulations has not received enough attention. Key research questions involve the coupling of valley and above-valley circulations. This coupling is a quite frequent phenomenon in the valleys of the western United States.

The recent improvements in understanding of the evolution of the valley's atmosphere during the inversion destruction period could be incorporated in algorithms, planning tools, simple models, or numerical models, and should provide an improved basis for the planning and conduct of future aerial spraying operations. 


\subsection{REFERENCES}

Bader, D. C. and C. D. Whiteman. 1989. "Numericai Simulation of Cross-Valley Plume Dispersion During the Morning Transition Period." J. Appl. Meteor. 28:652664.

Brehm, M. 1986. "Experimentelle und numerische Untersuchungen der Hangwindschicht und ihrer Rolle bei der Erwärmung von Tälern. [Experimental and Numerical Investigations of the Slope Wind Layer and its Role in the Warming of Valleys]." Wiss. Mitt. Nr. 54, dissertation, Universität München Meteorologisches Institut, München, FRG.

Gleeson, T.A. 1951. "On the Theory of Cross-Valley Winds Arising From

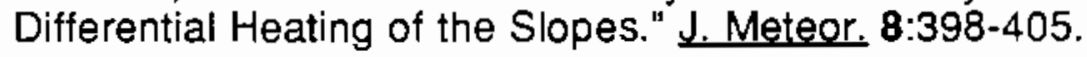

Hewson, E.W., E.W. Bierly, and G.C. Gill. 1961. "Topographic Influences on the Behavior of Stack Effluents." Proc. Amer. Power Conference. 23:358-370.

Start, G.E., C.R. Dickson, and L.L. Wendell. 1975. "Diffusion in a Canyon Within Rough Mountainous Terrain." J. Appl. Meteor. 14:333-346.

Urter-Henneberger, C. 1970. "Neure Beobachtungen über die Entwicklung des Schönwetterwindsystems in einem V-förmigen Alpental (Dischmatal bei Davos). [New Observations of the Development of a Clear Weather Wind System in a V-Shaped Mountain Vailey (Dischma Valley Near Davos)]." Arch. Meteor. Geophys. Bioklim., Ser. B 18:21-42.

Whiteman, C. D. 1982. "Breakup of Temperature Inversions in Deep Mountain Valleys: Part I. Observations." J. Appl. Meteor 21:270-289.

Whiteman, C. D. 1989. "Morning Transition Tracer Experiments in a Deep Narrow Valley." J. Appl. Meteor. 28:626-635.

Whiteman, C. D. 1990. "Observations of Thermally Developed Wind Systems in Mountainous Terrain." Chapter 2 in Current Directions in Atmospheric Processes Over Complex Terrain, (W. Blumen, Ed.), Meteorological Monographs. American Meteorological Society, Boston, Massachusetts, 5-42.

Whiteman, C. D., and K. J. Allwine. 1985. VALMET - A Valley Air Pollution Model. PNL-4728, Rev. 1. [Available from NTIS as PB86-104106/AS]. Pacific Northwest Laboratory, Richland, Washington.

Whiteman, C. D., and K. J. Allwine. 1986. "Extraterrestrial Solar Radiation on Inclined Surfaces." Environ. Software, 1:164-169.

Whiteman, C. D., and T. B. McKee. 1982. "Breakup of Temperature Inversions in Deep Mountain Valleys: Part II. Thermodynamic Model." J. Appl. Meteor., 21:290-302. 
PNL-7332

UC-402

\section{DISTRIBUTION}

No. of

Copies

\section{OFFSITE}

10 Dr. Robert Ekblad

U.S. Forest Service

Missoula Technology and

Development Center

Fort Missoula, Building 1

Missoula, MT 59801

2 DOE Office of Scientific and

Technical Information

\section{ONSITE}

DOE Richland Operations Office

16 Pacific Northwest Laboratory

J. C. Doran

J. W. Falco

J. M. Hales

P. C. Hays

J. V. Ramsdell

C. D. Whiteman (5)

Publishing Coordination

Technical Report Files (5) 


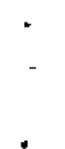

